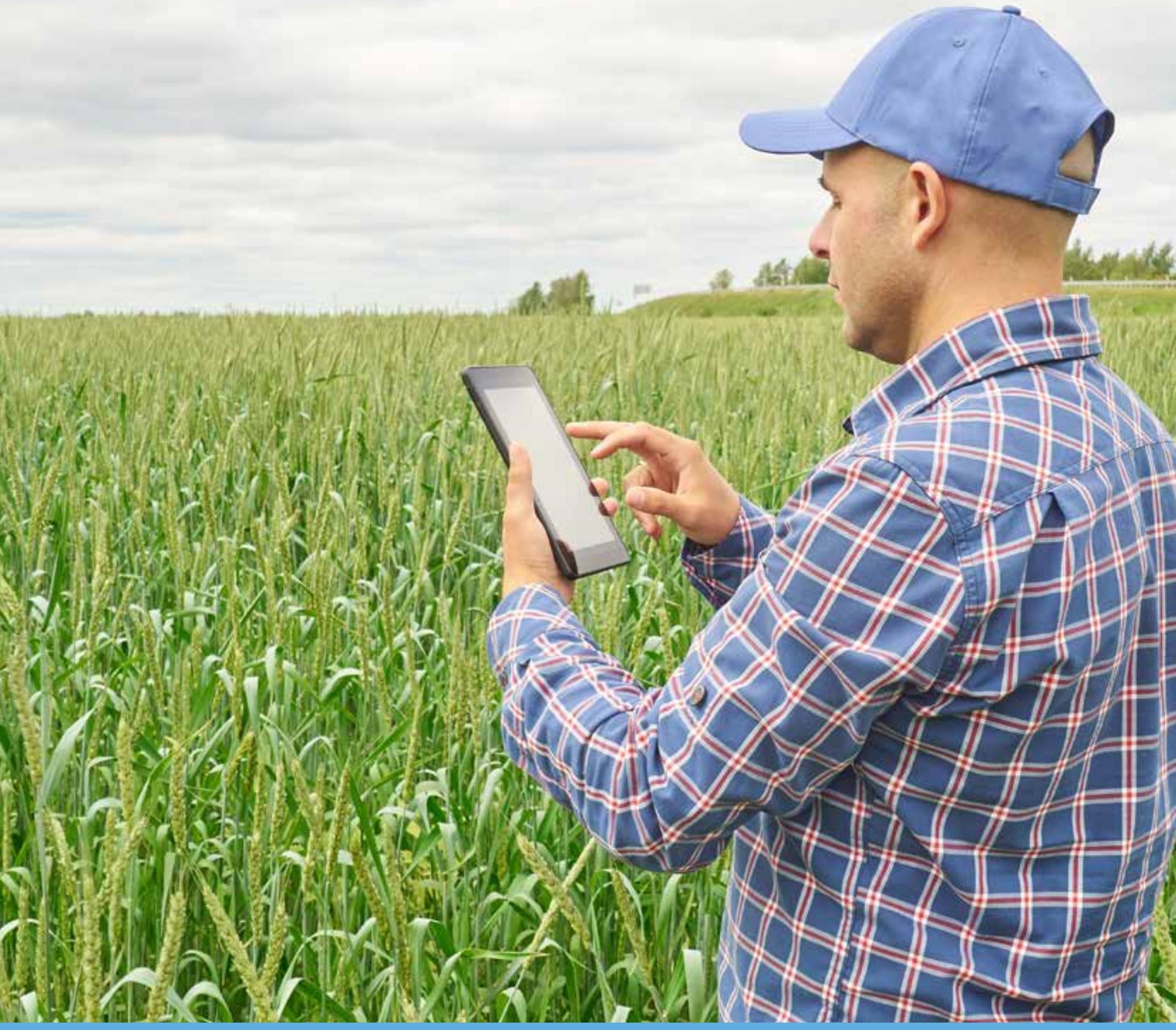

Impact Assessment for Digital Compliance Platform: A Conceptual Model

(D3.1.1 Conceptual model for impact assessment)

Lan Ge, Wil Hennen, Bart Doorneweert, and Marc-Jeroen Bogaardt

WAGENINGEN

U'FarmDigital 



\section{Impact Assessment for Digital Compliance Platform: A Conceptual Model}

(D3.1.1 Conceptual model for impact assessment)

Lan Ge, Wil Hennen, Bart Doorneweert, and Marc-Jeroen Bogaardt

This study was commissioned and financed by the Dutch Ministry of economic Affairs within the top sector 'Horticulture and propagation materials' and the top sector 'Agri-food'.

Wageningen Economic Research

Wageningen, October 2016

REPORT

2016-063

ISBN 978-94-6257-954-5 
Primo-Secundo, A., B. Tertio, C. Quarto, 2016. Impact Assessment for Digital Compliance Platform: A Conceptual Model; (D3.1.1 Conceptual model for impact assessment). Wageningen, Wageningen Economic Research, Report 2016-063. 22 pp.; 8 fig.; 2 tab.; 8 ref.

Key words: compliance platform, impact assessment, value network, farm information processes, Impact pathways, Indicators

This report can be downloaded for free at http://dx.doi.org/10.18174/392055 or at www.wur.eu/economic-research (under Wageningen Economic Research publications).

(C) 2016 Wageningen Economic Research

P.O. Box 29703, 2502 LS The Hague, The Netherlands, T +31 (0)70 33583 30,

E communications.ssg@wur.nl, http://www.wur.eu/economic-research. Wageningen Economic Research is part of Wageningen University \& Research.

\section{(cc) BY-NC}

For its reports, Wageningen Economic Research utilises a Creative Commons Attributions 3.0 Netherlands license.

(C) Wageningen Economic Research, part of Stichting Wageningen Research, 2016

The user may reproduce, distribute and share this work and make derivative works from it. Material by third parties which is used in the work and which are subject to intellectual property rights may not be used without prior permission from the relevant third party. The user must attribute the work by stating the name indicated by the author or licensor but may not do this in such a way as to create the impression that the author/licensor endorses the use of the work or the work of the user. The user may not use the work for commercial purposes.

Wageningen Economic Research accepts no liability for any damage resulting from the use of the results of this study or the application of the advice contained in it.

Wageningen Economic Research is ISO 9001:2008 certified.

Wageningen Economic Research Report 2016-063 | Project code 2282300102

Cover photo: Shutterstock 


\section{Contents}

$\begin{array}{ll}\text { Preface } & 5\end{array}$

$\begin{array}{ll}\text { Summary } & 6\end{array}$

1

$\begin{array}{ll}\text { Introduction } & \mathbf{7}\end{array}$

$\begin{array}{lll}1.1 & \text { Background } & 7\end{array}$

$\begin{array}{lll}1.2 & \text { Objective and scope of the study } & 7\end{array}$

$\begin{array}{lll}1.3 & \text { Structure of the report } & 8\end{array}$

2

$\begin{array}{ll}\text { Key Concepts } & 9\end{array}$

$2.1 \quad$ Impact Assessment 9

2.2 Platform $r$

$\begin{array}{lll}2.3 & \text { Farm information processes } & 11\end{array}$

$\begin{array}{ll}2.4 & \text { Value network }\end{array} 11$

$\begin{array}{llr}3 & \text { Impact Pathways and Indicators } & 13\end{array}$

3.1 Characterising the As-Is situation $\quad 13$

3.2 Conceptualisation of a compliance platform (To-Be) 14

$\begin{array}{lll}3.3 & \text { Spheres of impact and impact pathways } & 15\end{array}$

$\begin{array}{ll}3.3 .1 & \text { Spheres of impact }\end{array}$

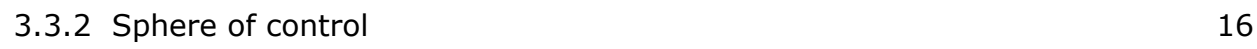

$\begin{array}{ll}3.3 .3 \text { Sphere of influence } & 17\end{array}$

$\begin{array}{ll}\text { 3.3.4 Sphere of interest } & 17\end{array}$

$\begin{array}{lll}3.4 & \text { Indicators and data needed } & 17\end{array}$

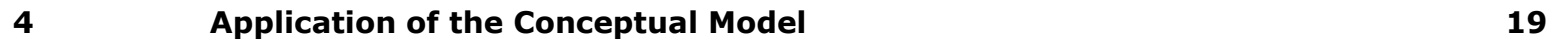

4.1 Characterisation of the baseline $\quad 19$

4.2 Characterisation of the intervention $\quad 19$

$\begin{array}{ll}4.3 \text { Confounding factors } & 19\end{array}$

$\begin{array}{ll}\text { References and websites } & 20\end{array}$ 



\section{Preface}

Growers in international chains participate in food safety and sustainability programmes in which they share information with customers and certification bodies. Digitalisation of the information and development of information standards for data exchange are expected to ease the administrative burden of data sharing. The project FarmDigital (www.farmdigital.nl) is set up to develop these standards and test a prototype compliance platform for collecting and sharing compliance data.

This report presents a conceptual model for impact assessment of the prototype compliance platform developed within the project FarmDigital. In view of the different degrees of direct and indirect interactions with the platform, the conceptual model distinguishes three spheres of impact: sphere of control, sphere of influence and sphere of interest. Furthermore, the model describes impact pathways of the digital compliance platform in different spheres of impact on different stakeholders. For the purpose of practical application, this report also discusses the indicators to be specified and data needs for future impact assessment.

This study was commissioned and financed by the Dutch Ministry of economic Affairs within the top sector 'Horticulture and propagation materials' and the top sector 'Agri-food'.

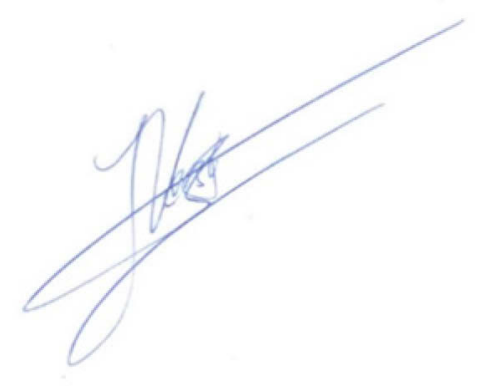

Prof.dr.ir. J.G.A.J. (Jack) van der Vorst General Director Social Sciences Group Wageningen University \& Research 


\section{Summary}

Growers in international chains participate in food safety and sustainability programmes in which they share data with customers and certification bodies. Digitalisation of the data and information standards for data exchange are expected to ease the administrative burden of data sharing. The project FarmDigital (www.farmdigital.n!) is set up to develop these standards and test a prototype compliance platform for collecting and sharing compliance data.

This report presents a conceptual model for impact assessment of the prototype compliance platform developed within the project FarmDigital. The platform is conceptualised as IT-based interorganisational arrangements in a value network. Stakeholders in the value network are connected to the platform in different ways and through different channels. In view of the different degrees of direct and indirect interactions of the stakeholders with the platform, three spheres of impact can be distinguished within the value network: sphere of control, sphere of influence, and sphere of interest. Based on the theory of change developed, the model describes impact pathways of the digital compliance platform in different spheres of impact.

The conceptual model can be used to specify indicators and derive data needs for empirical impact assessment. Following the conceptual model, it is important for impact assessment to characterise the baseline situation, the intervention, and the confounding factors. When assessing the impact of the prototype platform, the following confounding factors in the sphere of influence and the sphere of interest should especially be taken into account:

- Developments in the ag-data space (e.g., the rise of competitor platforms or competing technologies such as big data and Blockchain technologies and the availability and developments of information standards that are needed for data exchange)

- Developments in the certification landscape (e.g., changing demand for certification schemes, changing data requirements by certification schemes)

- Changing institutional environment (e.g., stringent regulations on data ownership, privacy)

- Changing ownership and governance structure of the future prototype platform (e.g., solely owned and operated by AgriPlace B.V., shared ownership by AgriPlace and DLO, collective ownership). 


\section{Introduction}

\section{$1.1 \quad$ Background}

Nowadays farming and agricultural products have to meet a wide range of environmental and social requirements. The Standards Map (http://www.standardsmap.org/), for example, lists over 170 sustainability standards and other similar initiatives covering issues such as food safety and labour conditions. The emergence of various sustainability standards and certification schemes in the agrifood sector reflects a profound need for reliable information on the quality of food products and production processes by various stakeholders for various purposes (Corporate Sustainability Initiative, 2010). Quality is interpreted here in a broad sense as the extent to which the attributes of food products and production processes meet the relevant norms and standards. Stakeholders are for example governments, NGOs, traders, retailers, financiers, and consumers.

To meet the demand for information and to prove compliance with relevant requirements, farmers in the agrifood chains must register and report all kinds of data. The majority of these agriculture-related data are still paper-based, spread over different systems and difficult to exchange between interested parties. There is an imperative need to improve the efficiency of information capture and information exchange by many parties involved. Against this background, digitalising agricultural business data and linking data from different sources has become an important item on policy and research agendas.

FarmDigital (www.farmdigital.n!) is a Public-Private Partnership research programme within the Dutch top sector policy (http://topsectoren.nl/english) that is developed in response to these developments. The two top sectors Horticulture \& Propagation Materials and Agri \& Food are striving for transparent agricultural supply chains to guarantee food safety, security and sustainability. To this end, the availability of reliable data and the efficiency in data exchange are essential. FarmDigital aims to contribute to these aspects by developing and marketing an open information infrastructure (OIA) that will enable users to freely exchange information about compliance data. Standardisation authorities, certification bodies, business communities and scientific groups all work together within FarmDigital, which is coordinated by LEI Wageningen UR to deliver results on the following three aspects:

1. Open Information Architecture

2. Prototype as 'Proof of Concept'

3. Business model and continuation.

Research on business model and continuation (work package 3) concerns four themes:

1. Impact of the prototype developed in work package 2

2. Business models for the compliance platform

3. Sector strategy to enhance digitalisation

4. Value and ownership of data.

This report results from the study on the impact of the prototype.

\subsection{Objective and scope of the study}

FarmDigital is a 'Design Oriented Research' within agriculture and horticulture, which means it focuses on solving problems by applying smart design in practice. A crucial point within 'Design Oriented Research' is the testing of the design through a 'Proof of Concept'. For this purpose, a prototype for a compliance platform, called Agriplace (https://www.agriplace.com/), is being developed and tested by the company Agriplace B.V., a wholly owned subsidiary of the People 4 Earth Foundation 
AgriPlace, as a prototype of FarmDigital, is envisaged as a digital compliance platform where growers can register and store compliance-related data and share the data with other parties. As a proof of concept, AgriPlace tests not only technical aspects of the open information architecture being developed within FarmDigital but also business aspects such as the potential impact on various stakeholders. By providing insights into the likely consequences, impact assessment of the prototype is important for the future development of FarmDigital in general and for the compliance platform in particular.

The objective of this study is to develop a conceptual model for impact assessment that can be operationalised for future evaluation purposes. The conceptual model contributes to the design and implementation of the business model. A conceptual model is understood as a descriptive model or diagram that shows the key elements in the system of interest and the hypothesised relationships between them. In the case of impact assessment, it provides an abstract representation of the impact to be expected by characterising the current situation, the actions being taken or to be taken, the pathways towards the impact, and the indicators that can be used to measure the impact. The conceptual model helps create shared understanding among project members and stakeholders on the current and future development of the compliance platform. An Excel model and a questionnaire have been developed that can be used for collecting data needed for estimating potential impact. Actual data collection and impact evaluation are beyond the scope of this study.

\subsection{Structure of the report}

Chapter 2 introduces key concepts regarding impact assessment and a compliance platform. In Chapter 3 we characterise the As-Is and To-Be situation for the purpose of impact assessment and present the impact pathways and indicators. Application of the conceptual model is discussed in Chapter 4. 


\section{Key Concepts}

\section{$2.1 \quad$ Impact Assessment}

Impact assessment is defined in various ways and may serve various purposes. It is essentially an assessment of lasting changes in the target of study that are likely to follow the intervention being considered and are relevant to the goal of the intervention. ${ }^{1}$ An intervention is a deliberate process by which change is introduced. The implementation of a policy programme is for example an intervention as it introduces changes to existing social-economic context. Similarly, the establishment of a compliance platform is an intervention as it may alter existing interactions and relationships in the business context in which it is established and will be operating. For this study, impact assessment is understood as the process of identifying and assessing the changes that the prototype platform is likely to incur.

\section{Theory of Change}

The foundation of impact assessment is the Theory of Change (ToC). A ToC is essentially a comprehensive description and illustration of how and why a desired change is expected to happen in a particular context. It provides a conceptual roadmap for how an organisation expects to achieve its intended impact and is often displayed in a diagram. Alternative causal paths may also be identified. The theory must also allow for the major external factors influencing outcomes.

A theory of change typically characterises the following questions:

- What is the current situation (As-Is) and what is the desired situation (To Be)?

- What strategies and channels are used to bring about the change?

- What activities will be taken?

- Who (actors or institutions) are or what is involved in the change?

- What consequences will these activities have?

- What are the contexts that affect how the change happens? (confounding factors)

- What is the process or pathway of change?

\section{Spheres of impact}

An intervention may affect and be affected by different actors in different contexts and in different degrees. We use three 'spheres of impact' to distinguish the scope and degree of impact the intervention may have:

- Sphere of control where the changes can be considered direct outputs of the intervention due to direct interactions between the intervention and the target group considered

- Sphere of influence Where the consequences are jointly influenced by the intervention and actions from other actors and factors

\section{- Sphere of interest}

Where the changes are relevant to the goal of the intervention, but are only indirectly influenced by it.

Figure 1 visualises the concept. Carving out different spheres of impact helps identify strategic focus and priority of the intervention. The demarcation of different spheres depends on the intervention being taken or to be taken. For example, the same solution provider may be located in the sphere of control when it is included as a member of the project consortium that functions as platform provider, but in the sphere of influence when it is outside of the project consortium.

\footnotetext{
1 https://www.ifpri.org/impact-assessment
} 


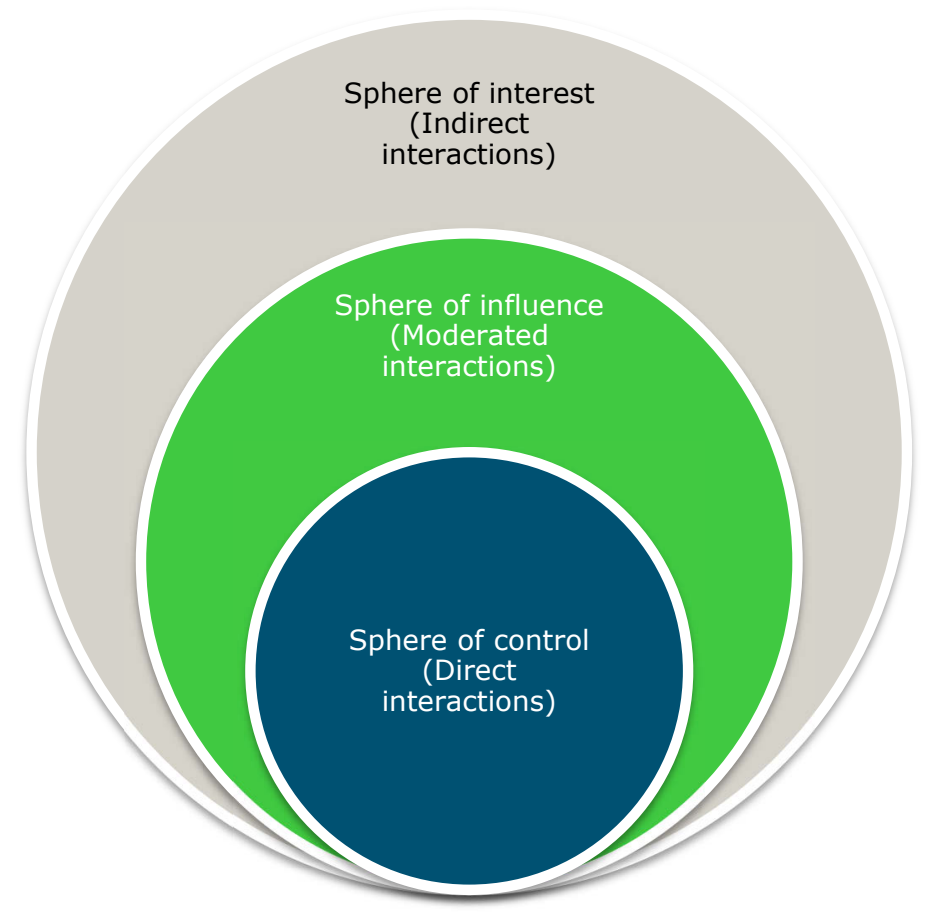

Figure 1 Three spheres of impact

\section{Impact channels and pathways}

Since the consequences of an action taken by any actor or institution are influenced by a myriad of other factors, impact assessment is known to be complex. The challenge with an intervention like the establishment of a platform is also its networked nature: the actions taken by others, whether or not in response to the development of the platform, can profoundly influence the course and result of the platform.

An effective strategy to address impact assessment challenges is to identify the channels and pathways by which project or programme outputs contribute to outcomes and impact.

\subsection{Platform}

Platforms are ubiquitous in today's digital economy. While platforms used to be understood as merely technical infrastructure for developing or running computer programmes, nowadays they are increasingly viewed as a technical and organisational context in which a community can interact to achieve a specific purpose (Klievink et al., 2015). Platforms can be considered IT-based interorganisational arrangements, in which the platform acts as an inter-organisational coordination hub (Markus and Bui, 2012). Dominant themes in literature on platforms include value creation, collaboration, business models and information infrastructure.

The conceptualisation of platforms as a socio-technical concept means that both the IT infrastructure (e.g. interfaces, tools, and services) and governance mechanisms (e.g. user groups, terms and conditions, decision-making structures) should be addressed in impact assessments. A platform is as much about the relationships between actors as it is about the technical platform itself. Platform governance refers to the solutions that organisations devise for problems of coordination. Governance and information infrastructure are thus interrelated aspects. 


\subsection{Farm information processes}

Information processes permeate every aspect of farm management and farming. Acknowledged or not, farmers today are managers, accountants, engineers and research pioneers all bundled into one. ${ }^{2}$ A farmer may assume multiple roles in these processes: data provider, data requestor, and data analyst. To assess the impact of a compliance platform like the prototype of FarmDigital, it is important to have insights into these processes and roles in the As-Is (baseline) and in the To-Be situation.

Figure 2 outlines the key steps that should be characterised.

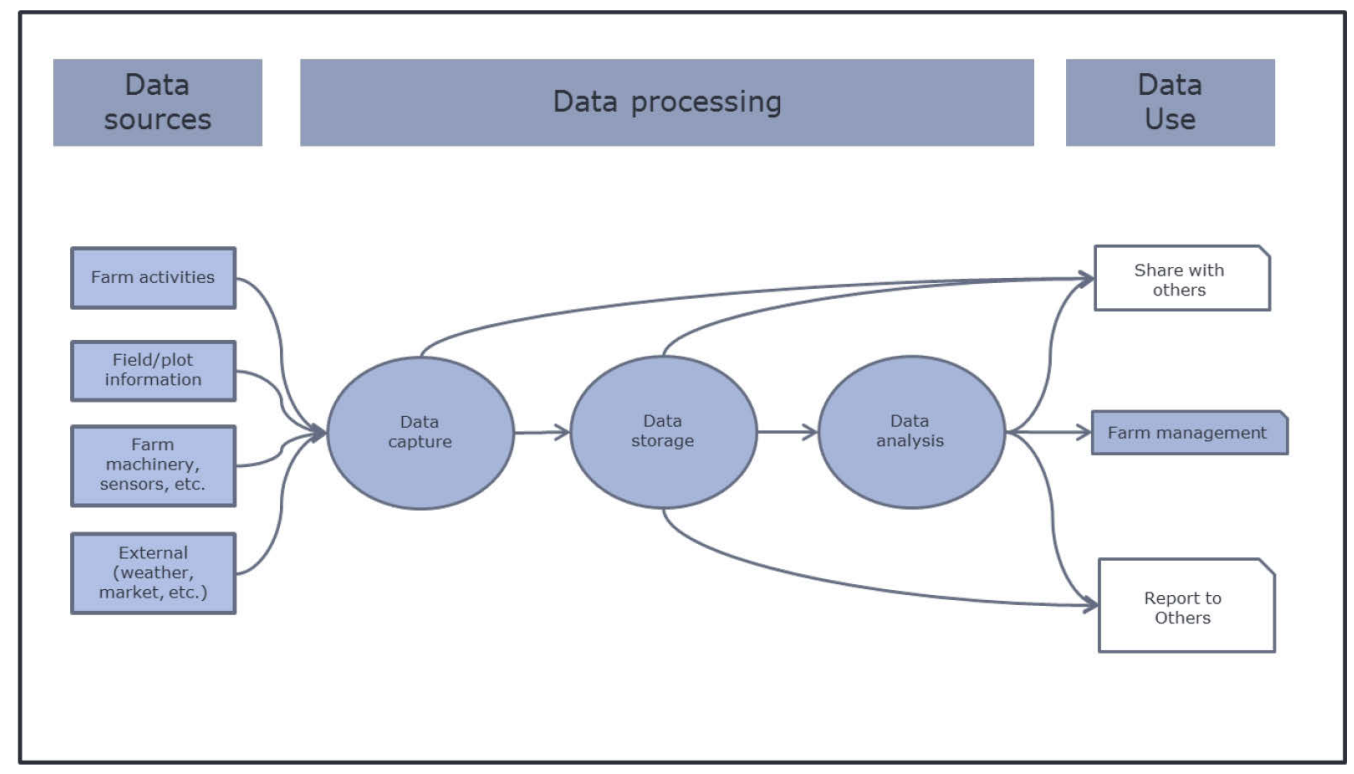

Figure 2 A simplified view of farm information processes

For the theory of change, it is important to keep in mind the following aspects in the As-Is situation of farm information processes:

- Different sources of compliance data

- Varying degrees of IT maturity among farmers

- Different requirements of compliance data per certification scheme or data requestor

- Different data sharing modes (obligatory reporting, voluntary compliance, etc.).

\section{$2.4 \quad$ Value network}

A value network is a business analysis perspective that describes social and technical resources within and between businesses. Value network analysis is a methodology for understanding the internal and external value networks and complex economic ecosystems (Peppard and Rylander, 2006). The methods include visualising sets of relationships from a dynamic whole systems perspective.

From a network perspective relationships are viewed as part of a larger whole - a network of interdependent relationships. These relationships are 'connected' since what happens in one relationship can affect other relationships. Adopting a value network perspective means looking at how the organisation creates value within the context of the network rather than viewing value creation

2 http://www.economist.com/blogs/schumpeter/2013/04/farming-apps 
from the perspective of an organisation as an isolated unit. It is this network of relationships that provides the key to understanding the competitive environment in the network economy.

By understanding an organisation's relationships with other network members, strategists can better understand the following:

- Where value lies in the network and how value is co-created

- How the organisation's activities will affect the network and

- How other members are likely to respond.

Figure 3 illustrates a simplified version of the value network in the As-Is situation where there is no compliance platform but stakeholders are connected through diverse flows of compliance information and other farm information. Part of the information flow passes through providers of farm management systems. In this network, some requestors of data (consumers, NGOs) have no direct interaction with the providers of data (farmer, cooperatives, etc.), but receive data through other actors in the network.

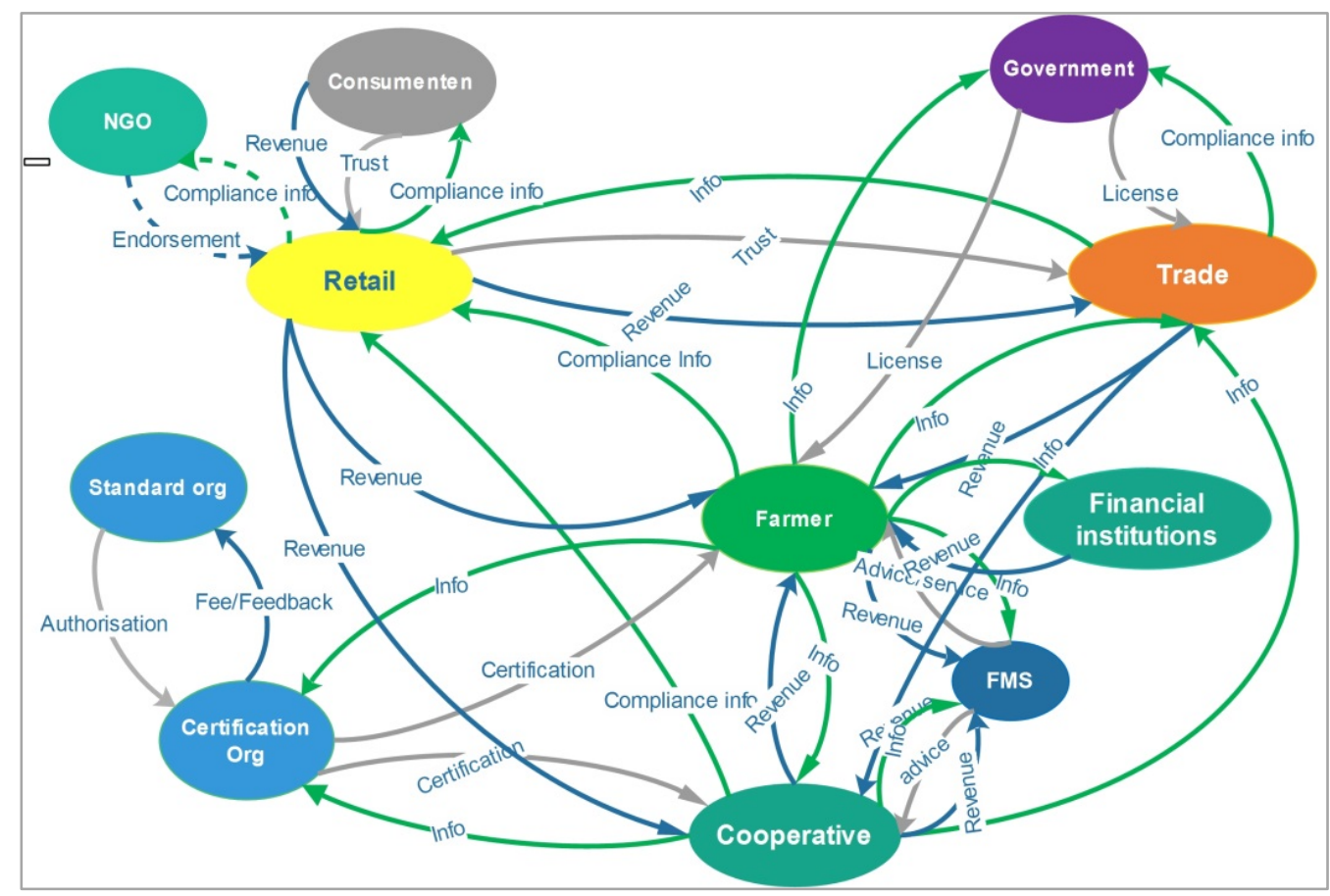

Figure 3 The value networks around the compliance platform of FarmDigital

Adopting a network perspective helps the analyst understand not only the direct relationships between the platform and its users, but also the interrelationships between all the other members of the network, which is a much more complex issue. Understanding and coping with such complexity is a major challenge in platform development. 


\section{Impact Pathways and Indicators}

\subsection{Characterising the As-Is situation}

\section{As-Is situation}

The key features of the As-Is situation relevant to the compliance platform are:

- Compliance data and related data are registered and shared in different ways

- Data are stored in different formats and in different systems

- Information is reported in different ways

- Little re-use of existing data.

The AS-IS situation is visualised in Figure 4.

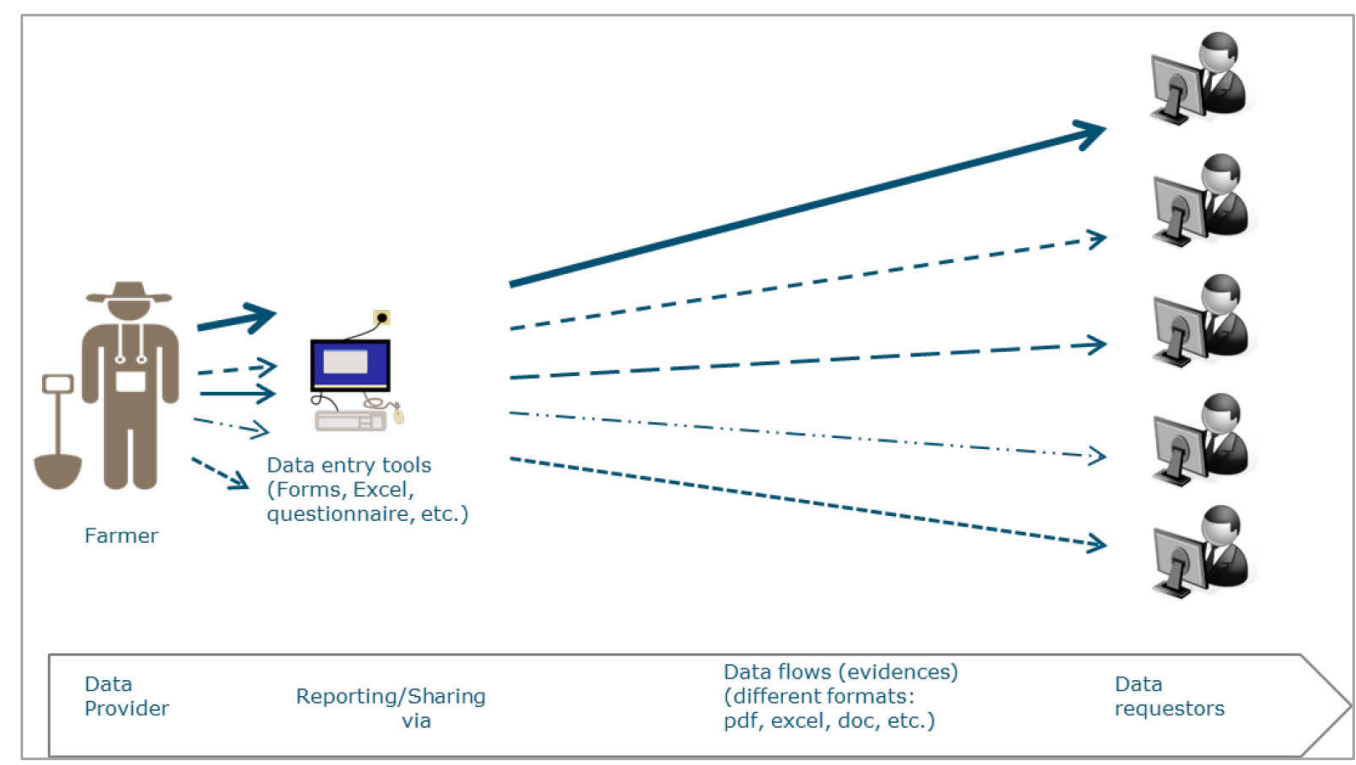

Figure 4 Simplified As-Is situation of farm information process

In the As-Is situation, it may be easier for individual companies and certification bodies to have farmers' supply data on an individual website. However, that does not lead to reusing or optimising the value of data, and it is not clear whether the farmer can take his data with him if he changes trading companies.

The problems resulting from these features have not gone unnoticed. Large ag tech corporations such as John Deere and Trimble, agribusiness giants like Monsanto, sustainability NGOs like Rainforest Alliance, Standard organisations like GLOBAL G.A.P, and other agribusiness partners are actively working on data-driven innovations (Esmeijer et al., 2015). Big data is poised to profoundly change farming practices. An ever-increasing number of start-ups are also keen on developing platforms and mobile applications for farmers all over the world ${ }^{3}$ (Drucker, 2014).

\footnotetext{
3 See for example in this document about 55 ag tech providers offering data services:

https://www. iowafarmbureau.com/f/c03924db-fcc4-4537-89aa-b5a1f18fb79c/agstate-final-appendix-1-atp-list-7-dec-14 and the database in websites such as https://agfunder.com/ and http://techcrunch.com/
} 


\section{IT-maturity: computer literacy, availability of farm management systems (FMS)}

The levels of IT-maturity can significantly vary across countries and sectors. For example, many Dutch farmers have a PC, but do not use farm management systems for business operations on farm or across supply chains. Providing ICT support for these chains, the Netherlands will strengthen its leadership role in international trade. On the other hand, although farm management systems in the current situation can offer data to other parties, they do not work in international chains, nor do they support all data. In the Netherlands, the PETA collaboration ${ }^{4}$ is trying to increase the market share of FMS by promoting a uniform information architecture. Similar initiatives are expected to further affect digitalisation and data exchange within the sector.

\section{Problems to be addressed}

The main bottleneck in compliance is that current standards have different categorisations with a very different and incomparable cross-sector view of the standard. It is expected that each standard categorises their concepts in a unique way, thereby impeding their comparisons and complete alignment (see Deliverable D1.2.1).

Administrative systems are being used more and more frequently to monitor and safeguard sustainability and food safety in the agricultural sector. A sizeable part of the administration is still paper-based, which is leading to unnecessary costs for organisations and growers. In addition, there are farmers in developing countries who cannot participate in such programmes.

Broader standards are needed. Value can be created for growers who have no farm management system (FMS) by making data available for multiple certification programmes. This will also deliver benefits for growers who do have an FMS by offering them access to more data (only some data can be derived from a FMS).

\subsection{Conceptualisation of a compliance platform (To-Be)}

Business-to-business (B2B) interactions are increasingly conducted through inter-organisational coordination hubs, in which standardised IT-based platforms provide data and business process interoperability for interactions among the organisations in particular industrial communities (Klievink et al., 2015). A compliance platform in the To-Be situation is such a coordination hub between different data providers and data requestors.

\section{To-Be situation}

The To-Be situation, visualised in Figure 5, is a new process addressing the problems from the AS-IS analysis.

Digital standards and a neutral platform would ease the administrative burden of growers in obtaining certification and reduce the workload of auditors to retrieve required information. The key features of the post-platform architecture in the To-Be situation are:

- Register once and report to many/share with many

- Reuse of data

\footnotetext{
4 The Project Elektronische Transactiedata Akkerbouw (PETA) initiative is a collaboration project between five Dutch cooperatives (Agrifirm, Suiker Unie, Nedato, CZAV and KMWP) with the aim to support data exchange among growers.
} 


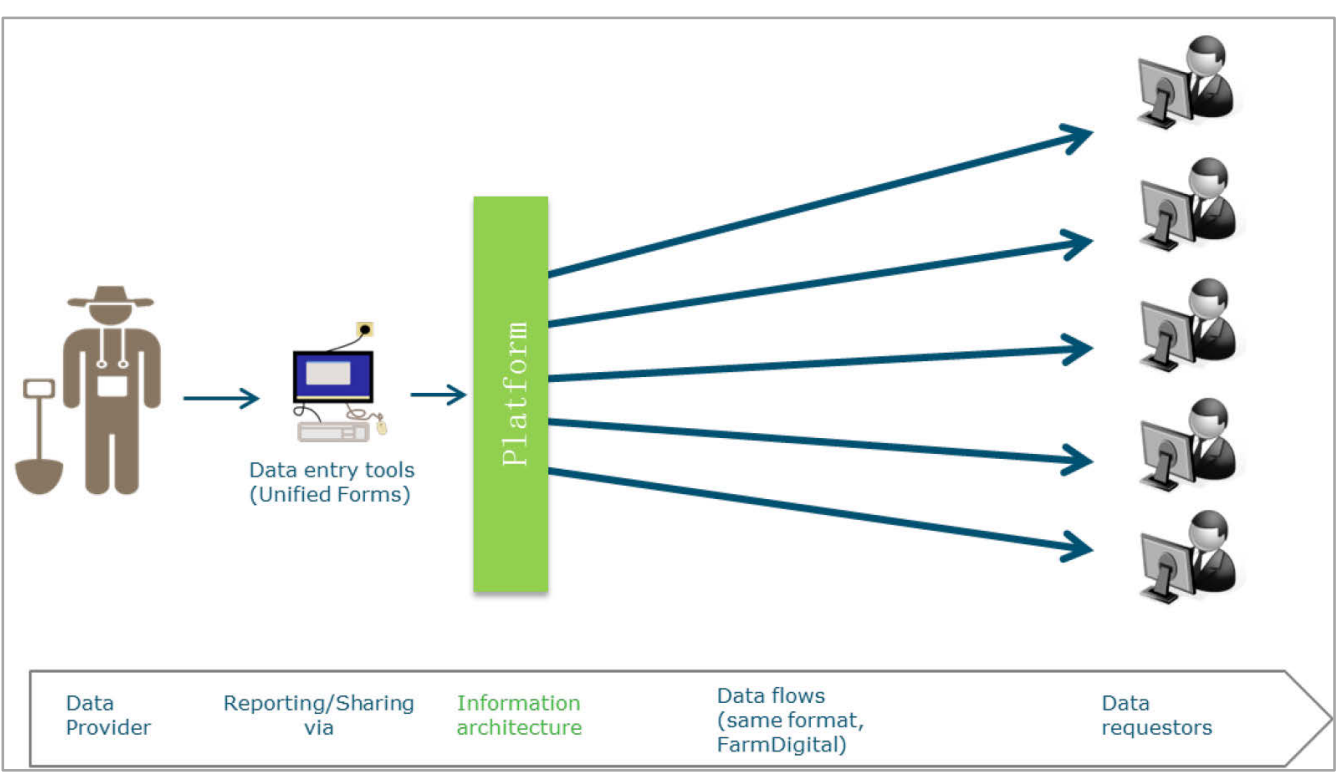

Figure 5 Simplified To-Be situation of farm data process with the compliance platform

\section{Architectural framework and information standards}

The architectural framework is described in detail in other deliverables of FarmDigital (e.g. Deliverable D1.2.1).

\subsection{Spheres of impact and impact pathways}

\subsubsection{Spheres of impact}

Stakeholders in the value network of the compliance platform are connected to the platform in different ways and through different channels. The development of a compliance platform has a direct impact on growers and auditors as users of the platform for compliance purposes, but no direct impact on growers who have no intention of obtaining certification.

Figure 6 visualises the pathways to impact through different spheres and stakeholder groups. Table 1 illustrates the different stakeholder groups in each sphere. The paragraphs that follow describe the pathways in more detail.

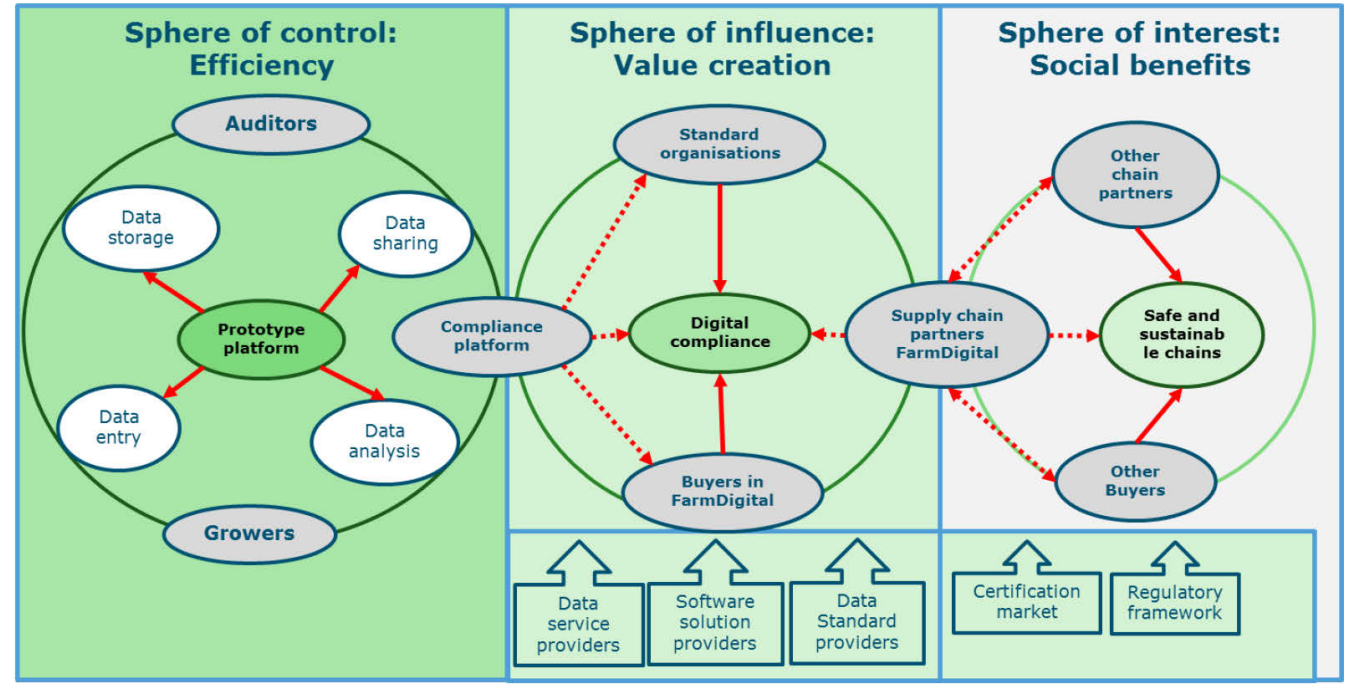

Figure 6

Spheres of impact from a compliance platform 
Table 1

Stakeholders in different spheres of impact

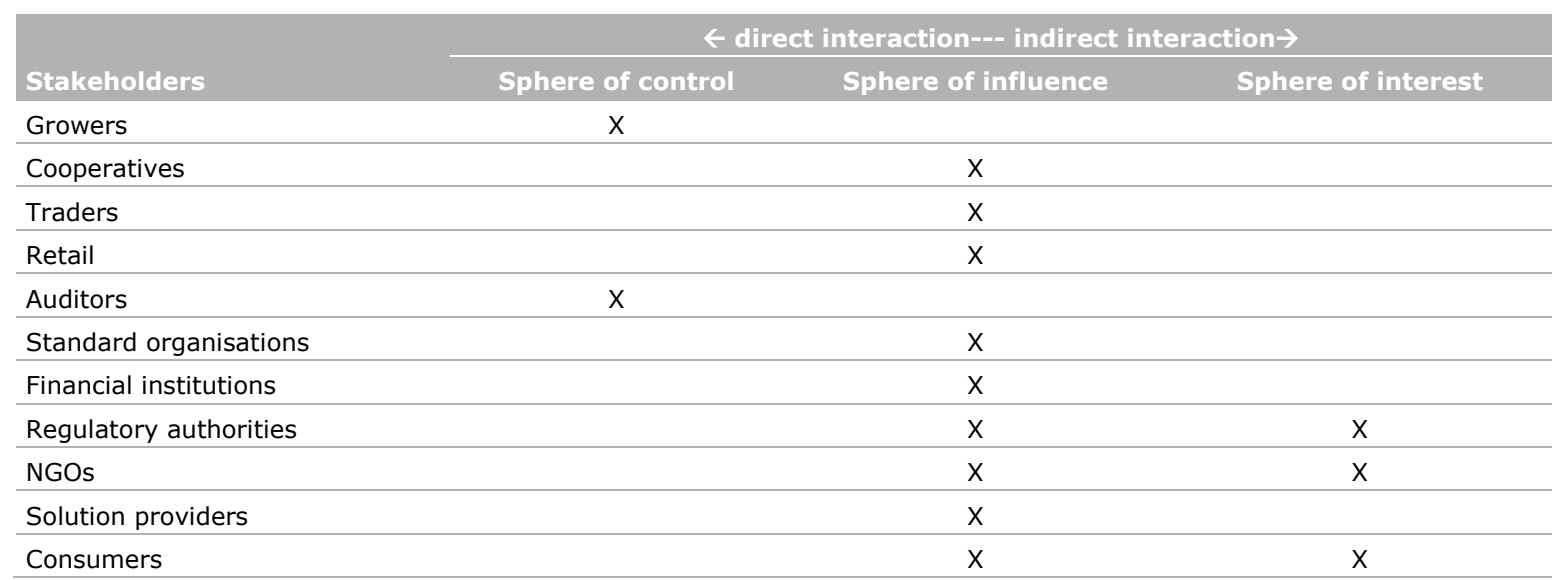

\subsubsection{Sphere of control}

Since the prototype aims to simplify the provision of data for compliance by providing tools for growers and auditors to capture and re-use the data (Figure 7), the data processes of growers and auditors are within the sphere of control of the platform.

To assess the impact of the prototype on existing farm information processes, it is important to take into account the As-Is situation in terms of the IT-maturity in each data process and the level of complexity in farm processes. Figure 7 shows the key steps that should be characterised:

- Data entry: How data are collected and recorded. The level of IT-maturity in this step can range from manually kept records on paper to automatically collected data through sensor or smart machinery.

- Data storage: How data are stored. This can range from paper-based archives, computer programmes, portable storage devices, to storage place in the cloud.

- Data exchange: How data are exchanged with other parties. This can range from paper-based exchange (e.g., postal exchange of manually kept or printed documents) to e-mail with PDF-type attachments. More advanced forms are automatic exchange through web-services or other electronic data-linkages.

- Data analysis: This concerns both the way in which data are analysed and the purpose for which data are analysed. Data can be analysed for example by visual inspection, general office software, specific software services or other packages. The purpose of data analysis can range from verification and validation of data to extraction of business intelligence to support decision making.

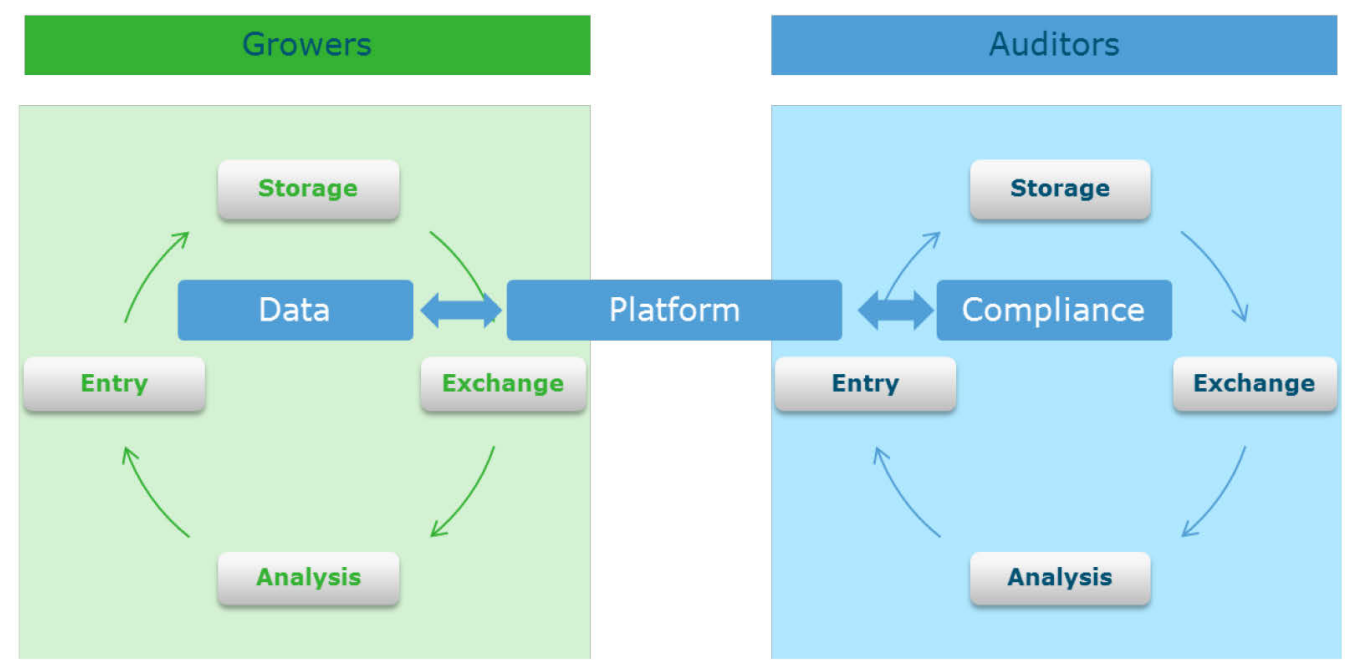

Figure 7 Digital compliance: primary data processes 


\subsubsection{Sphere of influence}

It is widely recognised that the governance of inter-organisational arrangements will affect the efficiency and effectiveness of the platform (Bharosa et al., 2015). This aspect is of particular importance in the sphere of influence where inter-organisational arrangements are inevitable. The advent of a new data-platform could pose threat to incumbents in data-driven businesses, but also creates new market as it expands the scope of the value network. In such cases, strategic alliance can possibly benefit both the new platform and the incumbent platforms or similar solution providers. For new platforms, it is advisable to consider a platform envelopment strategy through which a platform provider in a market can enter another platform market, and combine its own functionality with that of the target in a multi-platform bundle. Platform envelopment strategies make it possible to leverage common components and shared user relationships (Eisenmann et al., 2011).

A major concern for any data system is the coordination and authorisation of access. In a system that contains data that are in any way sensitive, whether it is confidential information, human resource data, or corporate intelligence, it is necessary to define a security and authorisation policy and to provide for its enforcement.

In the sphere of influence, an important stakeholder group is that of farm management solution providers, or vendors of farm management software. By farm management software, we refer to software that collects, synthesises and analyses data on farm business processes such as planning, budgeting, cost and inventory management and marketing. Farm management software in general aims to help farmers run their farm more efficiently and more profitably.

There is an explosion of agricultural software in the ag-tech software market. Ag software runs the gamut from basic business operations - reducing paperwork, improving productivity and enabling ecommerce - to specialties such as drone and robotic technology for overseeing fields, moisture levels, pesticide and fertiliser usage and equipment, as well as for predicting crop yields and commodity prices. With the rise of data-crunching agricultural software, farmers these days are digging as much in data as in dirt. ${ }^{5}$

\subsubsection{Sphere of interest}

Issues in the sphere of interest are relevant to the higher objectives of the intervention, but are considered beyond its control due to lack of direct interaction or the broad scope of such issues. Examples of such issues are sustainability of food chains, transparency, and food safety. Attribution of changes to the intervention is typically difficult to establish. Impact on such issues is usually only qualitatively described or stated.

\subsection{Indicators and data needed}

Figure 8 shows the type of indicators that can be used in different spheres of impact. The choice of specific indicators for impact evaluation depends on the specific intervention to be considered and should be further specified corresponding to the desired results. For the objective of 'making compliance easy', Table 2 lists the time and costs for growers and auditors as measurable indicators for efficiency gain.

The data needed for impact assessment depend on the scope of the impact assessment and the indicators chosen. Figure 8 shows the key indicators in each scope of the impact. These indicators can be further specified for the stakeholders involved. As an illustration, Table 2 specifies the indicators for growers and auditors in the sphere of control.

5 http://www.entrepreneur.com/article/252796 
Primary data on these indicators can be collected through surveys among users of the platform and their comparison groups.

Possible secondary data sources are the databases of certification organisations, agricultural census information (such as CBS), and survey information published in related studies.

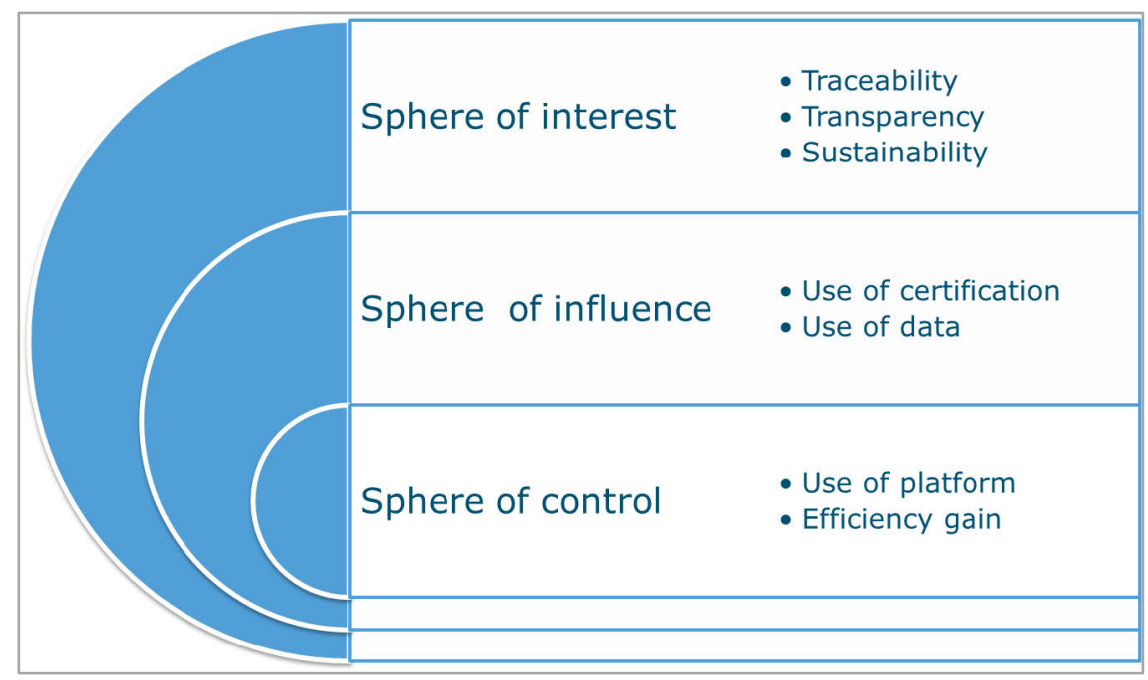

Figure $8 \quad$ Type of impact indicators in different spheres of impact

Table 2 Indicators for impact in the sphere of control

\begin{tabular}{lll} 
Sphere of control & Growers & Auditor \\
Use of platform & Number of growers using the platform & Number of auditors using the platform \\
& $\begin{array}{l}\text { Number of certification through the platform } \\
\text { Ease of use (qualitative) }\end{array}$ & Number of audits through the platform \\
& Ease of use (qualitative) \\
\hline Efficiency gain & $\begin{array}{l}\text { Change in time needed to prepare evidence } \\
\text { inspection }\end{array}$ & Change in time needed to retrieve compliance \\
& information and audit \\
\hline
\end{tabular}




\section{Application of the Conceptual Model}

\subsection{Characterisation of the baseline}

Following the conceptual model, the baseline situation (As-Is situation) can be characterised by the following aspects:

- The interactions among parties in the value network of compliance processes, more specifically: - The type, costs, and benefits of information exchanges between different parties (with focus on flows of compliance information as described in Deliverable 1.2.1).

- The type and amount of value exchange. Such value exchange can take the form of economic transactions or intangible values such as trust and reputation.

- IT maturity of the users in information processes (c.f. 3.3.2). The level of IT maturity in the As-Is situation can greatly influence the added value of the platform.

- Complexity of compliance processes. This can vary greatly across certification schemes, depending on the standards used, auditing procedures, data requirements, etc. High complexity of compliance processes may increase the demand for a compliance platform that simplifies the task, but also poses challenge to the technical design of the compliance platform.

- Time and effort spent on delivering compliance evidences (growers).

- Time and effort spent on obtaining compliance evidences (auditors).

\subsection{Characterisation of the intervention}

Platforms differ in functionalities and strategies employed to attract and engage users. Such differences imply different mechanisms by which the platform changes the As-Is situation and can lead to different results and outcomes. To assess the impact of a platform, it is therefore important to characterise the following two aspects:

- Platform functionalities: what are the tools and services offered by the platform? For whom are the tools and services developed? What was the actual use of the tools and services?

- Platform strategies: What on-boarding and engagement activities were carried out to attract users? How was the reach of the activities?

\subsection{Confounding factors}

Identifying the precise effects of an intervention is often a complex and challenging task due to many confounding factors that can cause or prevent the intended change of the compliance platform. Confounding refers to a situation in which the effects of two processes are not separated. When assessing the impact of the prototype platform, the following confounding factors in the sphere of influence and the sphere of interest should especially be taken into account:

- Developments in the ag-data space (e.g., the rise of competitor platforms or competing technologies such as big data and Blockchain technologies and the availability and developments of information standards that are needed for data exchange)

- Developments in the certification landscape (e.g., changing demand for certification schemes, changing data requirements by certification schemes)

- Changing institutional environment (e.g., stringent regulations on data ownership, privacy)

- Changing ownership and governance structure of the future prototype platform (e.g., solely owned and operated by AgriPlace B.V., shared ownership by AgriPlace and DLO, collective ownership). 


\section{References and websites}

\section{Literature}

Bharosa, N., Van Wijk, R., De Winne, N., and Janssen, M. (Eds.). (2015). Challenging the Chain: Governing the Automated Exchange and Processing of Business Information: IOS Press.

Corporate Sustainability Initiative. (2010). An Overview of Ecolabels and Sustainability Certifications in the Global Marketplace Research in International Business and Finance: Nicholas Institute for Environmental Policy Solutions, Duke University.

Drucker, V. (2014, 8 Sep 2014). Agriculture springs into the digital age. Fund Strategy, Sep 2014. Eisenmann, T., Parker, G., and Van Alstyne, M. (2011). Platform envelopment. Strategic Management Journal, 32(12), 1270-1285. doi: 10.1002/smj.935

Esmeijer, J., Bakker, T., Ooms, M., and Kotterink, B. (2015). Data-driven innovation in agriculture: Case study for the OECD KBC2-programme: TNO report TNO 2015 R10154.

Klievink, B., Bharosa, N., and Tan, Y.-H. (2015). The collaborative realization of public values and business goals: Governance and infrastructure of public-private information platforms. Government Information Quarterly, (in Press). doi: http://dx.doi.org/10.1016/j.giq.2015.12.002

Markus, M., and Bui, Q. (2012). Going Concerns: The Governance of Interorganizational Coordination Hubs. J. Manage. Inf. Syst., 28(4), 163-198. doi: 10.2753/mis0742-1222280407

Peppard, J., and Rylander, A. (2006). From value chain to value network:: Insights for mobile operators. European Management Journal, 24(2), 128-141.

\section{Deliverables within Farm Digital}

Deliverables from WP1: D1.2.1: Kruize, JW, Robbemond, RM, Verwaart, T., and Wolfert, J. (2015) Preliminary Architectural Framework

Deliverables from WP2

Interviews and communications with project consortium Farm Digital (in 2015)

- Coopertives Agrico, Fruitmasters, and LTO

- Retail: Jumbo

- Growers: ERF, Lobros

- Certifiers: Vinçotte ISACert

- FarmDigital Business Council Meetings (On June.26 and Nov.26, 2015)

- Stakeholder Panel workshop (On Nov.30, 2015) 
Wageningen Eonomic Research P.O. Box 29703

2502 LS The Hague

The Netherlands

$\mathrm{T}+31(0) 703358330$

E communications.ssg@wur.nl

www.wur.eu/economic-research

Wageningen Economic Research REPORT

2016-063
The mission of Wageningen University and Research is 'To explore the potential of nature to improve the quality of life'. Under the banner Wageningen University \& Research, Wageningen University and the specialised research institutes of the Wageningen Research Foundation have joined forces in contributing to finding solutions to important questions in the domain of healthy food and living environment. With its roughly 30 branches, 5,000 employees and 10,000 students, Wageningen University \& Research is one of the leading organisations in its domain. The unique Wageningen approach lies in its integrated approach to issues and the collaboration between different disciplines.

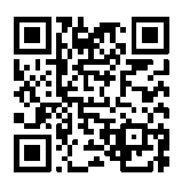





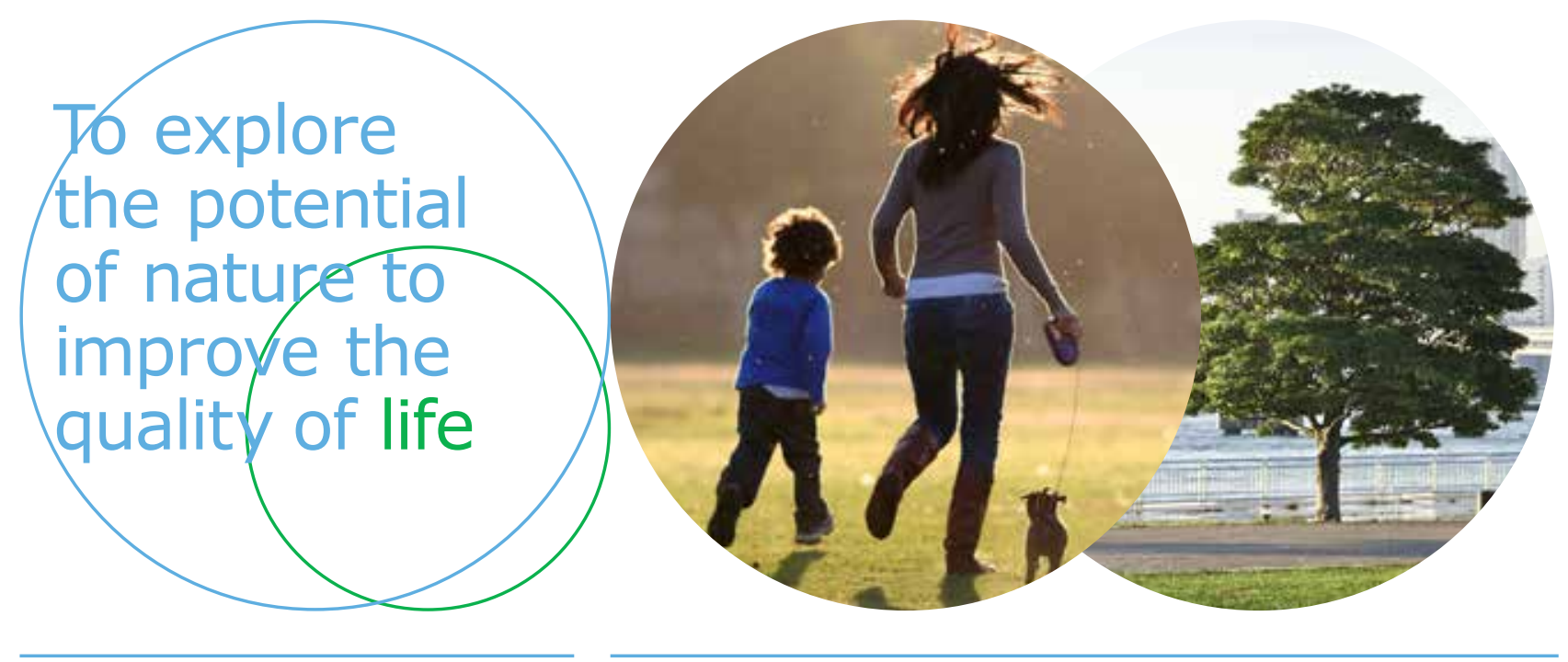

Wageningen Economic Research P.O. Box 29703

2502 LS Den Haag

The Netherlands

E communications.ssg@wur.nl www.wur.eu/economic-research

Report 2016-063

ISBN 978-94-6257-954-5
The mission of Wageningen University and Research is "To explore the potential of nature to improve the quality of life". Under the banner Wageningen University \& Research, Wageningen University and the specialised research institutes of the Wageningen Research Foundation have joined forces in contributing to inding solutions to important questions in the domain of healthy food and living environment. With its roughly 30 branches, 5,000 employees and 10,000 students, Wageningen University \& Research is one of the leading organisations in its domain. The unique Wageningen approach lies in its integrated approach to issues and the collaboration between different disciplines. 